University of Nebraska - Lincoln

DigitalCommons@University of Nebraska - Lincoln

Nebraska Cooperative Fish \& Wildlife Research Nebraska Cooperative Fish \& Wildlife Research Unit -- Staff Publications

2016

\title{
Management applications of discontinuity theory
}

\author{
David G. Angeler \\ Swedish University of Agricultural Sciences, david.angeler@slu.se \\ Craig R. Allen \\ University of Nebraska-Lincoln, callen3@unl.edu \\ Chris Barichievy \\ Zoological Society of London \\ Tarsha Eason \\ National Risk Management Research Laboratory \\ Ahjond S. Garmestani \\ National Risk Management Research Laboratory, garmestani.ahjond@epa.gov
}

See next page for additional authors

Follow this and additional works at: https://digitalcommons.unl.edu/ncfwrustaff

Part of the Aquaculture and Fisheries Commons, Environmental Indicators and Impact Assessment Commons, Environmental Monitoring Commons, Natural Resource Economics Commons, Natural Resources and Conservation Commons, and the Water Resource Management Commons

Angeler, David G.; Allen, Craig R.; Barichievy, Chris; Eason, Tarsha; Garmestani, Ahjond S.; Graham, Nicholas A.J.; Granholm, Dean; Gunderson, Lance H.; Knutson, Melinda; Nash, Kristy L.; Nelson, R. John; Nystrom, Magnus; Spanbauer, Trisha L.; Stow, Craig A.; and Sundstrom, Shana M., "Management applications of discontinuity theory" (2016). Nebraska Cooperative Fish \& Wildlife Research Unit -- Staff Publications. 227.

https://digitalcommons.unl.edu/ncfwrustaff/227

This Article is brought to you for free and open access by the Nebraska Cooperative Fish \& Wildlife Research Unit at DigitalCommons@University of Nebraska - Lincoln. It has been accepted for inclusion in Nebraska Cooperative Fish \& Wildlife Research Unit -- Staff Publications by an authorized administrator of DigitalCommons@University of Nebraska - Lincoln. 


\section{Authors}

David G. Angeler, Craig R. Allen, Chris Barichievy, Tarsha Eason, Ahjond S. Garmestani, Nicholas A.J.

Graham, Dean Granholm, Lance H. Gunderson, Melinda Knutson, Kristy L. Nash, R. John Nelson, Magnus Nystrom, Trisha L. Spanbauer, Craig A. Stow, and Shana M. Sundstrom 


\title{
REVIEW: QUANTIFYING RESILIENCE \\ Management applications of discontinuity theory
}

\author{
David G. Angeler ${ }^{1 *}$, Craig R. Allen ${ }^{2}$, Chris Barichievy ${ }^{3}$, Tarsha Eason ${ }^{4}$, \\ Ahjond S. Garmestani ${ }^{4}$, Nicholas A. J. Graham ${ }^{5}$, Dean Granholm ${ }^{6}$, Lance H. Gunderson ${ }^{7}$, \\ Melinda Knutson $^{8}$, Kirsty L. Nash ${ }^{5}$, R. John Nelson ${ }^{9,10}$, Magnus Nyström ${ }^{11}$, Trisha L. \\ Spanbauer $^{12}$, Craig A. Stow ${ }^{13}$ and Shana M. Sundstrom ${ }^{14}$
}

${ }^{1}$ Department of Aquatic Sciences and Assessment, Swedish University of Agricultural Sciences, Box 7050, SE-750 07 Uppsala, Sweden; ${ }^{2}$ U.S. Geological Survey - Nebraska Cooperative Fish \& Wildlife Research Unit, University of Nebraska, Lincoln, NE 68583, USA; ${ }^{3}$ Zoological Society of London, Regents Park, London NW1 4RY, UK; ${ }^{4}$ U.S. Environmental Protection Agency, National Risk Management Research Laboratory, Cincinnati, OH 45268, USA; ${ }^{5}$ ARC Centre of Excellence for Coral Reef Studies, James Cook University, Townsville QId 4811, Australia; ${ }^{6}$ U.S. Fish \& Wildlife Service, Bloomington, MN 55437-1003, USA; ${ }^{7}$ Department of Environmental Sciences, Emory University, Atlanta, GA 30322, USA; ${ }^{8}$ U.S. Fish and Wildlife Service, La Crosse, WI 54603, USA; ${ }^{9}$ Department of Biology-Centre for Biomedical Research, University of Victoria, Victoria BC V8P 5C2, Canada; ${ }^{10}$ Stantec Consulting Ltd., Saanichton BC V8M 2A5, Canada; ${ }^{11}$ Stockholm Resilience Centre, Stockholm University, SE-106 91 Stockholm, Sweden; ${ }^{12}$ Department of Earth and Atmospheric Sciences and School of Natural Resources, University of Nebraska, Lincoln, NE 68583, USA; ${ }^{13}$ National Oceanographic and Atmospheric Administration, Great Lakes Environmental Research Laboratory, Ann Arbor, MI 48108, USA; and ${ }^{14}$ School of Natural Resources, University of Nebraska, Lincoln, NE 68583, USA

\begin{abstract}
Summary
1. Human impacts on the environment are multifaceted and can occur across distinct spatiotemporal scales. Ecological responses to environmental change are therefore difficult to predict, and entail large degrees of uncertainty. Such uncertainty requires robust tools for management to sustain ecosystem goods and services and maintain resilient ecosystems.

2. We propose an approach based on discontinuity theory that accounts for patterns and processes at distinct spatial and temporal scales, an inherent property of ecological systems. Discontinuity theory has not been applied in natural resource management and could therefore improve ecosystem management because it explicitly accounts for ecological complexity. 3. Synthesis and applications. We highlight the application of discontinuity approaches for meeting management goals. Specifically, discontinuity approaches have significant potential to measure and thus understand the resilience of ecosystems, to objectively identify critical scales of space and time in ecological systems at which human impact might be most severe, to provide warning indicators of regime change, to help predict and understand biological invasions and extinctions and to focus monitoring efforts. Discontinuity theory can complement current approaches, providing a broader paradigm for ecological management and conservation.
\end{abstract}

Key-words: biodiversity, discontinuity theory, ecological complexity, extinction, invasion biology, management, monitoring, regime shifts, resilience, scale

\section{Introduction}

The human domination of the world's ecosystems has resulted in a biodiversity crisis with unprecedented species extinctions threatening ecosystems and the provisioning of ecosystem services upon which humanity relies (Barnosky et al. 2011). Rapid climate and landscape changes have led to the alteration of biogeochemical cycles, habitat fragmentation, emergence of new diseases and other changes that are best characterized as nonlinear transitions between ecosystem regimes (Holling 1973). Worstcase scenarios include undesired regime shifts (see Appendix S1, Supporting information for definitions of 
terms in italics) at the global scale with uncertain outcomes regarding the ongoing delivery of ecosystem services (Hughes et al. 2013).

Scientists and natural resource managers must strategically allocate limited resources for research, management and conservation of ecosystems. Robust tools are needed to characterize cause and effect relationships between stressors and ecological responses. These tools may reduce uncertainties, allow effective management to prevent ecosystems from tipping into undesired alternative states and facilitate the restoration of systems currently in undesired or degraded states. A major challenge for management is how to assess and manage for variability in structural and functional attributes of a system, while still ensuring system integrity, a central tenet of resilience theory (Gunderson 2000). Such system-level management requires an understanding of feedbacks and scale (Rietkerk et al. 2004). Investigations into the cross-scale organization of a system, in particular the distribution of pattern and process across various spatial and temporal extents, have taken centre stage in the search for indicators of imminent system change (Kefi et al. 2007). Understanding the organization of ecosystems by explicitly accounting for the scaling patterns present has a clear relevance for management (Kerkhoff \& Enquist 2007).

Here, we propose approaches to ecological management that utilize discontinuity theory, and argue that such strategies could help deliver better management outcomes for complex ecological systems. We briefly discuss the status of discontinuity research and then highlight the application of discontinuity approaches for meeting management goals. In particular, we focus on their potential for understanding resilience, to objectively identify critical scales of space and time in ecological systems, to provide indicators of regime change, to help predict and understand biological invasions and extinctions and to focus monitoring efforts.

\section{Discontinuities and the organization of ecosystems}

Ecosystems are hierarchically organized. Ecological patterns manifest, and processes operate, at distinct scales of space and time (Wiens 1989; Levin 1998). At each scale (i.e. spatial or temporal extent), a few variables dominate ecological processes. These lead to characteristic patterns and structures that change with scale and that provide different ecological systems with unique patterns of structure and process within and across scales (Angeler, Göthe \& Johnson 2013). In a simplified example drawn from marine zooplankton, there are small-scale patterns that affect individual zooplankton: migration, predation and competition occur in scales of $\mathrm{cm}^{3}$ to $\mathrm{m}^{3}$ in space and from hours to days in time, set in a larger-scale pattern of surface areas ranging from tens to hundreds of $\mathrm{km}^{2}$ and upwelling events occurring annually, to even larger-scale patterns that include the processes that cover hundreds to thousands of $\mathrm{km}^{2}$ over centuries and millennia (currents and oceanic fronts) (Haury, McGowan \& Wiebe 1978).

Despite the hierarchical organization of ecosystems across discrete spatiotemporal scales, processes at lower scales can permeate up to influence processes at higher hierarchical levels, for instance, when matter flows in food webs through a chain of organisms that perceive their environment at distinct spatial and temporal scales (from microscopic phytoplankton to krill to whales), and which therefore operate in distinct scaling regimes (Levin 1992). Similarly, processes at higher hierarchical scales (predation) can cascade down to affect processes at lower scales (primary production), highlighting the dynamic nature of these hierarchical structures (Gunderson \& Holling 2002). Such hierarchical and interlinked dynamics have been documented in many social and ecological systems (Allen et al. 2014).

Holling (1992) hypothesized that the cross-scale organization of ecological systems is ultimately mirrored in the structure of animal communities, positing that behavioural, life-history and morphological attributes of animals adapt to discontinuous environmental patterns because these patterns reflect opportunities for food, shelter and other resources. Indeed, Holling (1992) found a correlation between breaks in distributions of animal body mass, an integrative variable allometric with many ecological attributes (Peters 1983), and discontinuities in structures and processes in the boreal forest of Canada. He interpreted aggregations of species (or modes) along body mass distributions as scales at which resources and structure are available to organisms that have evolved to exploit resources at these specific scales (Fig. 1a). This means that species within the same body mass aggregation interact more with each other than with species in other aggregation groups, all else being equal. In contrast, gaps (discontinuities or troughs) in the distribution reflect the transition between structuring processes and thus scaling regimes (Fig. 1a). At these transitions, there are fewer ecological structures or resources with which animals can interact, or there is greater variance and instability in these structures or resources (Allen \& Holling 2008).

Holling's theory regarding the discontinuous organization of ecosystems has contributed substantially to our understanding of the complexity that is inherent in ecosystems and a range of other systems (e.g. social and economic; Garmestani, Allen \& Gunderson 2009; Sundstrom et al. 2014). This theory has proved useful for operationalizing quantitative approaches in resilience research that are needed to address the many challenges and uncertainties associated with rapid environmental change. Below, we review how discontinuity theory has contributed to our understanding of the resilience of ecosystems and describe other core areas where a discontinuity approach may provide novel insight, and improve our ability to manage complex ecological systems. 


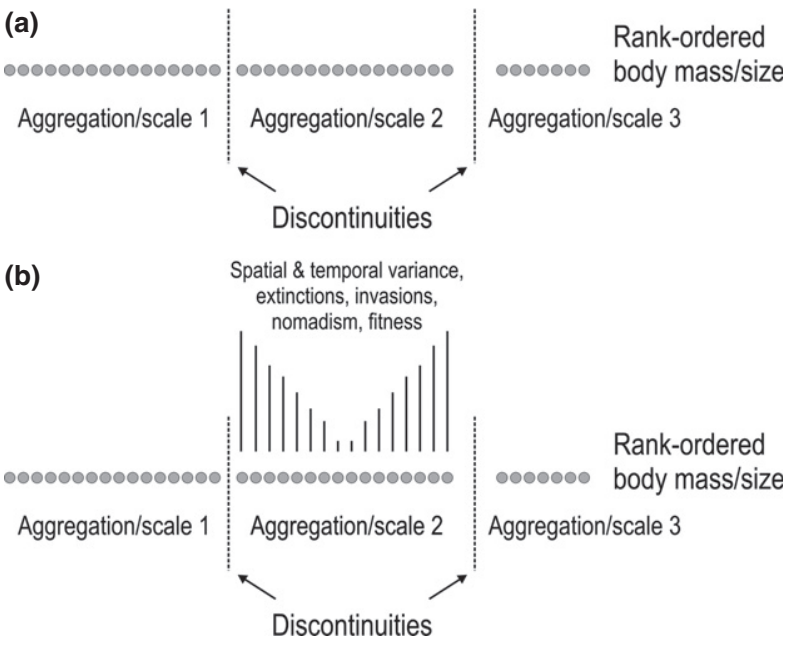

Fig. 1. Conceptual overview of the discontinuity approach. (a) Species (individual dots) within a community or population are rank-ordered [from low (left side of figure) to high (right)] with respect to body mass/size (log-transformed). Discontinuities or gaps (vertical dotted lines) are identified statistically and separate species into aggregation groups of species with similar body mass/ size. These aggregation groups putatively mirror scale-specific structure and processes in ecosystems, while the discontinuities reflect transition zones or 'scale breaks'. (b) The figure also emphasizes the non-randomness of ecological phenomena (e.g. nomadism, fitness, extinction) within body mass/size aggregation groups with higher variability occurring close to transition zones and stability in the centre of aggregation groups. The variability is shown by black vertical lines; that is, decreasing lengths of lines from the edges towards the centre of aggregations shows decreasing variability.

\section{Management application of discontinuity approaches}

\section{QUANTIFYING RESILIENCE}

Peterson, Allen \& Holling (1998) operationalized Holling's ideas related to cross-scale structure and resilience in ecosystems in the cross-scale resilience model, which accounts for scale in understanding the relationship between biodiversity and resilience. The cross-scale resilience model complements other methods aimed at quantifying ecological resilience, for example the assessment of thresholds or regime shifts (Standish et al. 2014). It differs from other approaches focusing on engineering resilience that typically emphasize the time needed for ecosystem attributes to recover after disturbances (Pimm 1991). The cross-scale resilience model is based on the notion that ecological functions and processes, and ultimately ecosystem resilience, depend on the distribution and diversity of functional traits, including effect and response traits, of species within and across spatiotemporal scales (Fig. 2). Several aspects of biodiversity are relevant for understanding this model: functional redundancy, response diversity and the scales at which functional trait attributes of species operate and overlap.

Within a single scale, resilience increases with an increasing redundancy of functional traits among species'

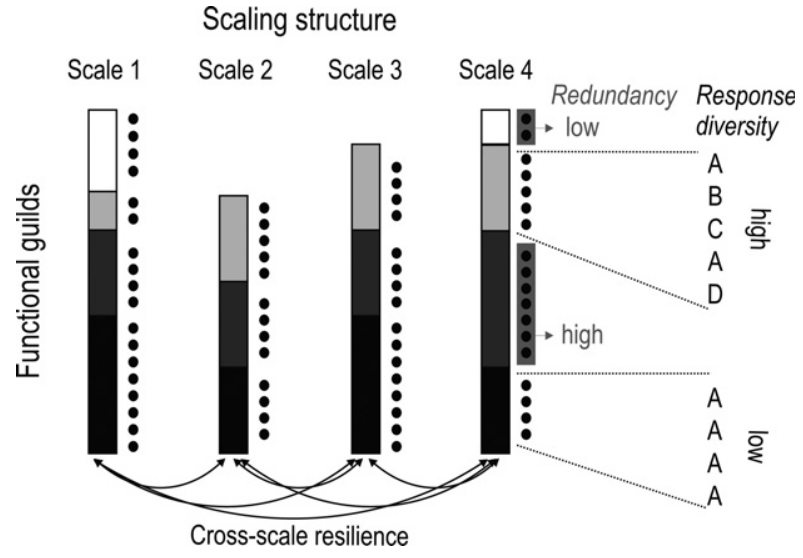

Fig. 2. Cross-scale resilience model showing the distribution of functional guilds (squares with different shades of grey) and the number of species in each guild (redundancy; species represented by black dots) across scales. Shown are examples of low and high redundancy and response diversity. The latter is indicated by letters indicating variability in the composition of multiple functional traits of species (e.g. A = slow growth, low dispersal; $\mathrm{B}=$ fast growth, low dispersal; $\mathrm{C}=$ fast growth, high dispersal; $\mathrm{D}=$ slow growth, high dispersal) and that confer different response potential of species to disturbances. Cross-scale resilience is indicated by arrows connecting individual scales. In this example, the white guild has the lowest cross-scale redundancy.

functional groups (Allen, Gunderson \& Johnson 2005). Redundancy describes the capacity of species to compensate the loss of any other species within a functional group, thereby maintaining the function of that particular group (e.g. grazing, pollination, predation). For instance, in coral reefs, sea urchins compensate for the loss (overfishing) of grazing fish, thereby maintaining herbivory (Nyström 2006). Response diversity (Elmqvist et al. 2003) refers to the range of responses a functional group possesses against environmental change, meaning that if response diversity is low, many species will be similarly affected by a perturbation. It is clear that both redundancy and response diversity need to be high in order for resilience to be high (Fig. 2). Finally, resilience also depends on species within functional groups that operate at different scales, contributing to cross-scale resilience (Allen, Gunderson \& Johnson 2005) (Fig. 2). Similar to the insurance effect (Yachi \& Loreau 1999), cross-scale resilience helps maintain ecological functions when species of functional groups operating at contrasting scales are affected differently by scale-specific disturbances. Crossscale resilience is expected to increase with the number of scales a function is present in a system (Allen, Gunderson \& Johnson 2005).

Within the ecological sciences, many researchers have studied functional community aspects in connection with Holling's discontinuity hypothesis to quantify resilience in both terrestrial and aquatic ecosystems (Nash et al. 2014a). For instance, a study evaluating the impact of the hypothetical loss of all threatened and endangered grassland birds to cross-scale resilience found that substantial 
losses could be absorbed without the loss of functionality within or across scales (Sundstrom, Allen \& Barichievy 2012). However, there were clear thresholds of loss after which system resilience would be so reduced that any further losses would eliminate critical functional redundancy across scales, or functional diversity within scales. Similarly, a study that analysed forest and woodland birds in fragmented agricultural landscapes found that bird communities subjected to human impacts were less resilient due to the selective extinction of particular body mass and functional groups (Fischer et al. 2007).

These examples show that discontinuity analyses can provide clues for understanding the cross-scale organizational structure of ecosystems and, consequently, their resilience. Extending research beyond evaluating body mass distributions to also assessing discontinuities in, for example, abiotic templates, biomass and process rates will allow us to test for generalities of the discontinuous organization of ecosystem attributes. Clarifying the explicit spatial patterns and temporal dynamics of these attributes may provide insight to help refine our understanding of resilience and inform management. The following examples show further how discontinuity approaches can be used in management.

\section{DETECTING DISCONTINUITIES AND IDENTIFYING SCALES}

The assessment of scale in ecological systems is important because disturbances, including those resulting from environmental change, affect ecosystems in scale-specific ways (Nash et al. 2014a). An understanding of scale-specific processes provides managers with a realistic assessment of vulnerabilities and the resilience of ecosystems to environmental change. Explicit consideration of 'intact' and 'affected' scales in analyses of global change impacts provides opportunities to tailor more specific management plans. For instance, management can be matched to target the reinforcement of critical ecological functions at those scales that are relatively free from stress to buffer against the potential loss of functions at affected scales, thereby fostering ecosystem resilience (Angeler, Allen \& Johnson 2013).

While such an approach is theoretically appealing, in practice, the selection of scales in ecological research is often arbitrary in nature. In landscape ecology, a widespread approach used to understand the effects of structure at various scales on populations, communities and their habitat use is to draw buffers of various sizes around a focal area, and to collect metrics from these increasingly large buffers (Fig. 3). Similarly, important scales may be defined through the simple delineation of local habitat vs. regional scales in metacommunity ecology (Leibold et al. 2004), or distinguishing between reach, catchment and intercatchment scales by aquatic ecologists (Allan \& Castillo 2007). Thus, the selection of scale in such studies is generally subjective (Wheatley \& Johnson 2009) and typi-
Definition of scale:
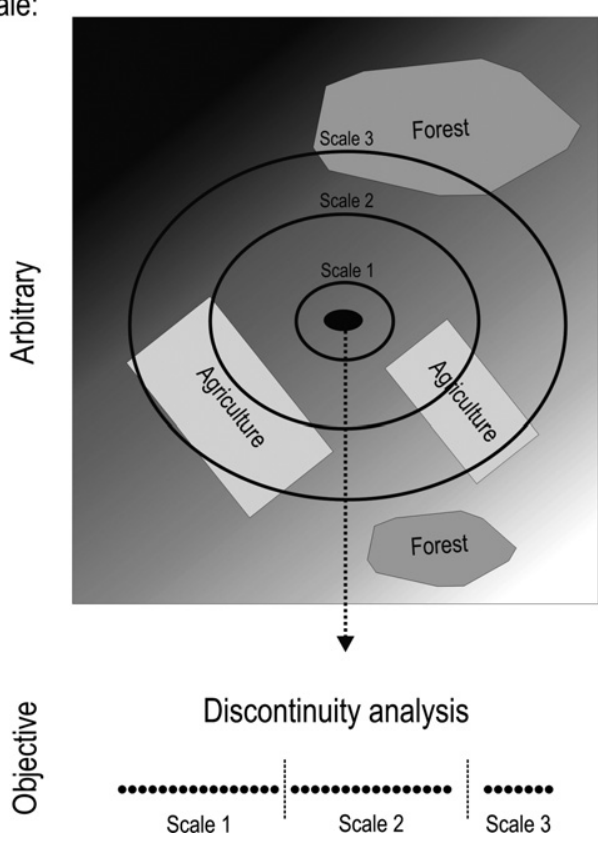

Fig. 3. The fallacy of spatial buffering to identify multiple scales on landscapes. Shown is a focal habitat (e.g. lake) located in a matrix that transitions between biomes and with different landuse types (forest patches and agricultural lands). Circles around this habitat show arbitrarily defined scales at different spatial extents that accurately capture neither the transitional dynamics nor the land-use patterns in this hypothetical landscape. Shown is also an approach for scale identification based on the discontinuity approach [black dots comprising species that organize in body size/mass aggregation groups, separated by scale transitions (vertical dotted lines)]. In the latter approach, the species present in the lake community integrates both local and regional processes in this hypothetical landscape that occur at distinct spatial and temporal scales.

cally reflects the analyst's view about which connections are important to the study at hand and which can be ignored. However, rather than arbitrarily assigning scales, or a priori assuming what the most critical scales are, scales of analysis can be objectively identified.

Discontinuity analysis provides a critical tool to objectively identify scales in ecological and other complex systems, including social systems (Sundstrom et al. 2014). The approach is appealing for natural resource managers because it can utilize a proxy (such as body mass) for the delineation of scales. Scales may be identified and resilience evaluated as follows. First, discontinuities can be assessed by collecting size or mass data for a representative sample of organisms from an ecosystem and analysing the distribution of body sizes or mass for 'gaps' in the distribution (Figs 1 and 2). Several statistical methods, including cluster analysis and classification and regression trees and their Bayesian implementations, exist for objectively identifying discontinuities in body mass/size data (Stow, Allen \& Garmestani 2007). These methods can be adjusted to account for differences in the life-history traits of organisms (e.g. species with determinate vs. indeterminate growth; Nash et al. 2014b). Secondly, resilience can 
be evaluated by studying the distribution of functional traits within and across identified scales and assessing redundancy and response diversity following the crossscale resilience model.

Resources for data acquisition, processing and evaluation are always limited, often compromising species detection and the evaluation of their abundances (Elphick 2008). These constraints invariably restrict the extent and scope for research and management. Assessments of scales based on discontinuity approaches do not strictly require the evaluation of abundances. Since body size or mass of organisms can be used to objectively identify scales inherent in ecological systems (Allen \& Holling 2008), costs arising from sampling evaluation can be reduced. Therefore, assessing scales and resilience based on body mass or size seems particularly suitable for habitats with limited monitoring data.

The identification of scales and analysis of discontinuities is not restricted to body mass/size data, giving flexibility to the approach. When monitoring data are available, the discontinuity approach can be extended to evaluate scaling patterns in time series and reveal environmental factors that correlate with these scaling patterns (Angeler et al. 2014a). For example, analysis of long-term data has revealed discrete groups of lake invertebrate species that exhibited distinct temporal frequencies. Some invertebrate species responded to slow environmental variables (recovery from acidification and climate change) and others responded to fast variables that were unrelated to environmental change (Angeler, Allen \& Johnson 2013).

Discontinuity theory can also be applied in a spatial context. In landscape ecology, Urban, O’Neill \& Shugart (1987) describe how components in a hierarchical system are organized into scales, which reflect defined landscape units in which processes operate. A landscape is decomposed into fundamental units, that is spatially discrete patches whose internal structure or function is significantly different from that of its surroundings (Burnett \& Blaschke 2003). This spatial representation of scale-specific patterns and processes is explicitly recognized in the hierarchical patch dynamics paradigm (Wu \& Loucks 1995). The discontinuous structure of pattern and process has been empirically demonstrated in landscapes (Gillson 2004), for example animal movement patterns in response to resource distribution (Fauchald \& Tveraa 2006) or scale-specific distribution of functional feeding groups of invertebrates in a stream network (Göthe et al. 2014) and lake landscape (Angeler et al. 2015a).

Time-series analysis and spatial modelling can be carried out on the presence-absence, abundance, density, biomass and coverage data, allowing for a broader application of discontinuity approaches across organism groups and ecosystems. While discontinuity analyses have been effective for identifying the number of dominant scales present in animal communities, there has been little application in other taxonomic groups with modular growth and that lack body mass/size data, such as plants. Kerkhoff \& Enquist (2007) have shown an elegant approach to evaluate scaling relationships (based on power laws) in forest ecosystems using tree density and diameter in forests. Therefore, metrics like density or diameter may also be amenable to analysis using the discontinuity approach to identify scaling patterns. Alternatively, time-series modelling and spatial modelling allow for the application of discontinuity theory to these groups (Angeler et al. 2014a). Many of these methods can be used to assess discontinuities in the abiotic environment and therefore have research potential in the hydrological, ecotoxicological and geochemical sciences to address management issues related to water quality and pollution. These examples highlight the usefulness of an extended discontinuity framework for objectively assessing the broader impacts of human activities in the environment, and their management relevance.

\section{DETECTING REGIME CHANGES}

Drivers of change (e.g. temperature, nutrient load, fishing and grazing pressure) can exceed a critical value (i.e. threshold) generating abrupt and unexpected shifts in ecosystem structure, processes, feedbacks and functioning, called regime shifts (Graham et al. 2015). These shifts can have huge implications for human well-being and societal development since different ecosystem services can be associated with certain regimes. Consequently, staying away from thresholds is of high concern for managers and policymakers. However, it is often unclear when critical thresholds are exceeded, and the effects of a regime shift may not become evident until ecosystems have reorganized into a new, often stable and possibly undesirable state. Adaptive approaches that emphasize proactive and incremental management based on changing ecological conditions are needed to help avoid regime shifts. In contrast, transformative approaches that focus on adaptation to novel ecosystem states are required when systems irreversibly lock into a new regime (Kates, Travis \& Wilbanks 2012).

Recognition of temporal change in ecosystems, including slow transitions (that often manifest over centuries or millennia) vs. abrupt change (that occurs often within decades) (Fig. 4a), can facilitate the identification of management approaches. A recent example exploring the detection of transitional and abrupt change comes from Foy Lake (USA). Using 8000 years of fossil diatom data for Foy Lake, Spanbauer et al. (2014) showed that transitions between alternative community regimes (i.e. different species' assemblages of diatoms) can take more than 2000 years, with the lake stabilizing into a new regime at c. 2200 years before present. A complementary analysis (T.L. Spanbauer, C.R. Allen, D.G. Angeler, T. Eason, S.C. Fritz, A.S. Garmestani, K.L. Nash, J.R. Stone, C.A. Stow \& S.M. Sundstrom, unpublished data) indicated a more rapid (decadal) regime shift in size data of the diatoms that occurred at c. 2400 years before present (Fig. 4b).

The inability of discontinuity analysis to highlight the 2000-year transition between lake regimes suggests that 

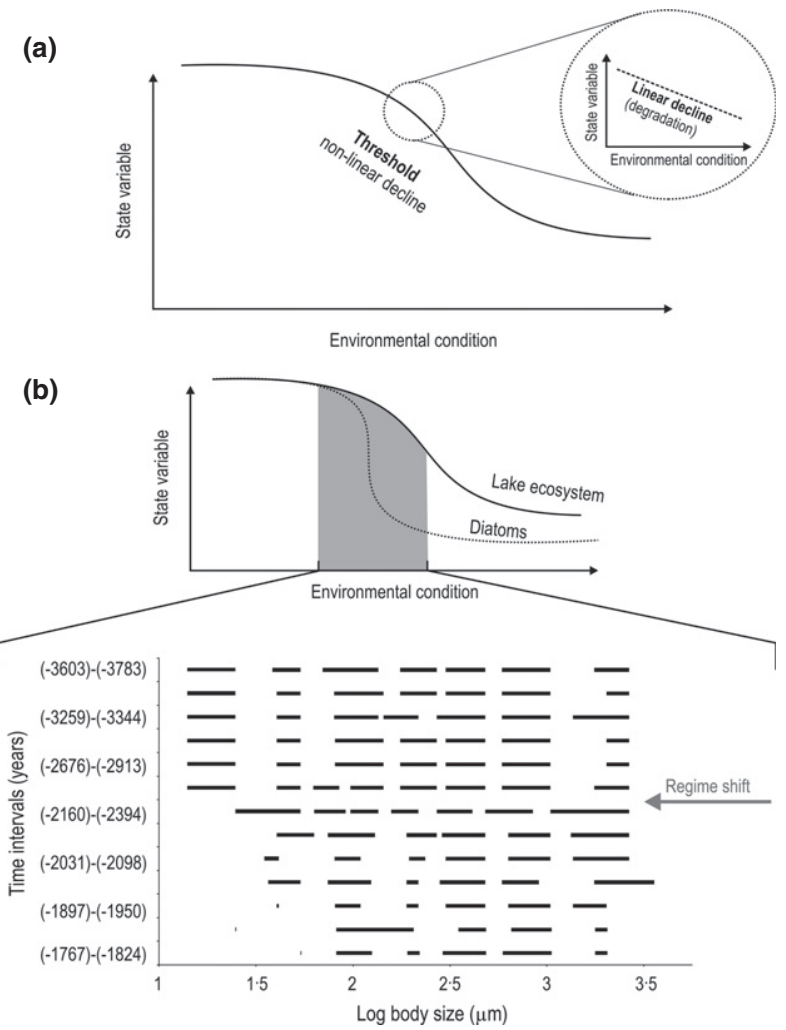

Fig. 4. (a) Graph illustrating linear vs. nonlinear regime changes in ecosystems, depending on the time-scale of observation. (b) Showing lake response curve (solid line) and the threshold in diatom community structure (dotted line) over time. The shaded area covers a period, comprised of several time intervals, before and after a regime shift, shown by the discontinuous structure in the Foy Lake (USA) diatom community. The regime shift is evident in the overall change in patterns of the aggregation groups comprising size ranges comprised of different diatom species within each group (lines) separated by gaps (absence of diatoms with specific sizes; white areas)

the millennial transition detected in Spanbauer et al. (2014) essentially comprises a slow erosion of Foy Lake's regime before it stabilized in a new regime. Nonetheless, discontinuity analysis uncovered a bifurcation point in the lake 200 years earlier than in Spanbauer et al. (2014), suggesting discontinuities could provide an avenue to uncover bifurcation points in ecosystems before a slowly evolving regime shift becomes systemic. We acknowledge that the application of discontinuity theory in the regime shift context is still very limited and that ecological dynamics operating at time-scales from centuries to millennia may seem intangible for today's managers and policymakers; however, recognizing transitional dynamics in ecosystems gives managers the opportunity to develop interventions towards safer conditions before the new regime eventually locks in and equilibrates (Hughes et al. 2013). Once a system has stabilized in an alternative regime, identified through discontinuity analysis, management can be transformed to focus on dealing with novel ecosystem conditions. The example from Foy Lake shows that discontinuity analysis is likely a valuable addition to the current toolbox of regime shift indicators, complementing other methods (Lindegren et al. 2012).

\section{EXTINCTION AND INVASION RISK, POPULATION AND COMMUNITY VARIABILITY}

Discontinuity theory has provided a more mechanistic understanding of ecological phenomena that concern ecologists and managers and has particular relevance for community and population ecology: invasions, extinctions, population fitness, migration and nomadism. Empirical analyses have shown that the location of species within body mass aggregations is non-random with regard to these ecological phenomena (Fig. 1b). The following examples come from a limited number of studies in different ecosystems; however, a common thread emerges from these, and this commonality highlights the potential of discontinuity research to refine ecological theory, ecological management and conservation.

Ecologists have shown that high trophic level, low population density, slow life history and small geographical range size are correlated with a high extinction risk in declining species (Purvis et al. 2000). In turn, these factors seem to correlate with a gradient in body size, with organisms at one end of this gradient (larger-bodied species) facing a greater extinction risk than organisms at the opposite end of this gradient (smaller-bodied taxa) (Gaston \& Blackburn 1995). The discontinuity approach allows for a more refined assessment of extinction risks because it examines the sensitivity of extinction along the breadth of this gradient. That is, it accounts for nonlinear patterns and scale-specific structures that are present in the environment (e.g. distribution and abundance of food, shelter and other resources) that influence the discontinuous body mass distributions of organisms (Holling 1992). For instance, bird, herpetofauna and mammal species with body masses that located them closer to discontinuities were more likely to be threatened or endangered in the Florida Everglades, USA (Allen, Forys \& Holling 1999). This extinction risk arises because of a greater variability and increased unpredictability of resource availability closer to discontinuities, which reflect transitions between scaling regimes in ecosystems (Holling 1992), and it may also be related to some of the factors (e.g. low population density, small geographical range size) identified by Purvis et al. (2000). Limited and more variable resources translate directly to higher population variability in both space and time, which has been further documented for bird species with body masses close to discontinuities (Wardwell \& Allen 2009).

Proximity to discontinuities as a zone of ecological instability for organisms that translates directly into greater spatial and temporal variability in communities has been further substantiated in studies of migration and nomadism. Bird species in Mediterranean ecosystems of central-south Australia with body masses located closer to discontinuities have a higher incidence of nomadism than 
those species with body masses in the centre of aggregation groups (Allen \& Saunders 2002, 2006). The latter species are often sedentary and occupy habitats with relative stability in terms of resource availability in time and space. Migrations, which are predictable and directional, and nomadism, which reflects unpredictable movements, require birds to locate resources in complex landscapes, particularly in ecosystems that exhibit high variability in resource abundance in time and space (Boyle \& Conway 2007). Thus, migration and nomadism may represent an evolutionary adaptation of organisms with specific body masses to cope with uncertainty in resource availability and abundance.

In the absence of such adaptations, it is likely that organisms that are sedentary or that have seen their migration patterns disrupted due to human impact (e.g. habitat loss, fragmentation and alteration) face increased extinction risk due to enhanced competition for limited and variable resources (May 1973; Pimm 1991). Evidence for this increased extinction risk comes from a recent study of fitness in European eel Anguila anguila populations. The eel is a diadromous species that completes its life cycle through migration between European inland waters and the Sargasso Sea (north-western Atlantic Ocean). Angeler et al. (2014b) found that individuals of eel populations in pristine Spanish streams had lower fitness when their body masses placed them closer to discontinuities. Interestingly, eel populations showed the opposite pattern in dammed streams that disrupted migration patterns, as higher fitness was associated with a body mass that placed them closer to discontinuities. In other words, eels that had body masses that placed them close to a discontinuity were more successful in degraded systems where resources are arguably more variable, while eels with body masses that placed them far from the discontinuities were more successful in pristine streams where resources ought to be more stable. The patterns found for the eel were also found for another threatened fish species (Mediterranean barbel Barbus meridionalis), but were not evident in invasive (common carp Cyprinus carpio) or tolerant fish species with stable populations (chub Squalius cephalus). While the mechanisms generating these contrasting patterns are unclear, the results suggest that individuals with body masses close to discontinuities may have a disproportionally higher tolerance to perturbations than those located in the centre of aggregation groups. From an applied viewpoint, this non-random pattern of sensitivity suggests that discontinuity analysis can be used to scrutinize patterns of conservation risks in populations and communities, allowing for more targeted management schemes for threatened species.

In the context of conservation risks, discontinuity analysis also has the potential to address relevant issues related to invasive species, which often have significant ecological and economic impacts. The success of invasive species has been explained by two contrasting but not mutually exclusive views, including intrinsic (functional traits) and extrinsic (ecological and genetic influences such as release from natural enemies, hybridization or other novel ecological and evolutionary interactions) factors (Colautti et al. 2014). Assessing the relative importance of these factors would benefit management, including the creation of 'blacklists' of potentially harmful species and 'whitelists' of species unlikely to pose a significant threat (Hui et al. 2011). However, despite the availability of powerful statistical methods, an analysis of invasion risk and success is often limited by data on, for instance, abundance, survival rates and reproductive output (Colautti et al. 2014). Also, uncertainty is added because modelling results can differ between scales of observation (Hamilton et al. 2005). Using body mass in the analysis, the discontinuity approach provides a complementary alternative to currently used methods in invasion biology, because it allows accounting for relevant scales in the analysis. Preliminary research has shown a higher likelihood of successful invasions if the body masses of the invaders fall close to discontinuities in the body mass distributions (Allen, Forys \& Holling 1999; Allen 2006). Ecologically, this may reflect zones where invasive species can more efficiently use resources than native species, that is areas where ecological niches are not saturated and competition with native species minimized. Given that species invasions are one of the principal problems related to environmental change (Lockwood, Hoopes \& Marchetti 2007), further research using discontinuity concepts to assess invasions across ecosystems and organism groups seems warranted. More broadly, the non-randomness of ecological phenomena, combined with the ability to identify scale-specific impacts and ultimately resilience of ecosystems, offers ecologists and managers alternative ways for monitoring and thus managing biodiversity and ecosystems, based on discontinuity approaches. We show this potential in our last example of management application of discontinuity theory.

\section{IDENTIFICATION OF MONITORING TARGETS}

Resources for monitoring programmes are always limited. Programmes are therefore often geared towards endangered and flagship species, such as charismatic vertebrates, taxa of socioeconomic interests (e.g. game fish species) or umbrella species that are believed to serve as a conservation surrogate for many other species (Carignan \& Villard 2002). However, these approaches have limitations because they can be costly, the identification of monitoring targets (variables or species that accurately reflect ecosystem processes) may not be a transparent procedure, conservation goals based on individual species may conflict, and ecological surrogates may not be very effective (Simberloff 1998; Rodrigues \& Brooks 2007). Advances have been made to overcome some of the limitations related to surrogacy, for instance, through the use of long-term monitoring data of multiple taxon groups at multiple sites along broad spatial gradients (e.g. the Swed- 
Table 1. Comparison of management and monitoring actions, with some pros and cons, under a traditional management paradigm vs. an approach utilizing a discontinuity approach. Some examples of management applications are given

\begin{tabular}{|c|c|c|c|}
\hline $\begin{array}{l}\text { Management or } \\
\text { monitoring action }\end{array}$ & Traditional approach & Discontinuity approach (DA) & Management applications of DA \\
\hline Assessing resilience & $\begin{array}{l}\text { Focus often on engineering } \\
\text { resilience (i.e. recovery time } \\
\text { after disturbances) }\end{array}$ & $\begin{array}{l}\text { Focus on ecological resilience } \\
\text { Accounting for scales and } \\
\text { ecological complexity; } \\
\text { complements other methods } \\
\text { based on, for instance, spatial } \\
\text { and time-series modelling, } \\
\text { regime shift detection, scaling } \\
\text { law descriptions } \\
\text { Using cross-scale resilience } \\
\text { model; quantifying scale-specific } \\
\text { distributions of functional traits }\end{array}$ & $\begin{array}{l}\text { Identification of ecosystems } \\
\text { vulnerable to environmental } \\
\text { change } \\
\text { Identify location of thresholds } \\
\text { Assess alternative states }\end{array}$ \\
\hline $\begin{array}{l}\text { Identification of } \\
\text { scales }\end{array}$ & $\begin{array}{l}\text { Subjective; observer-defined } \\
\text { Generally driven by jurisdictional } \\
\text { or geographic boundaries } \\
\text { Not connected to scales of } \\
\text { ecological processes }\end{array}$ & $\begin{array}{l}\text { Objective; identified through } \\
\text { statistical approaches } \\
\text { (discontinuity analysis, } \\
\text { time series and } \\
\text { spatial modelling) } \\
\text { Addresses ecological reality } \\
\text { Data may not be available at } \\
\text { scales coinciding with } \\
\text { ecological processes }\end{array}$ & $\begin{array}{l}\text { Identify scales of perturbation } \\
\text { Determine functional redundancy } \\
\text { and response diversity within } \\
\text { and across scales to drive } \\
\text { management focus } \\
\text { Match administrative scales } \\
\text { to ecological scales }\end{array}$ \\
\hline $\begin{array}{l}\text { Detecting regime } \\
\text { changes }\end{array}$ & $\begin{array}{l}\text { Focus on successional changes; } \\
\text { regime shifts implicit }\end{array}$ & $\begin{array}{l}\text { Explicit recognition of existence } \\
\text { of alternative regimes in } \\
\text { ecosystems }\end{array}$ & $\begin{array}{l}\text { Assessment of: } \\
\text { Thresholds necessary for } \\
\text { understanding restoration } \\
\text { Impending regime shifts }\end{array}$ \\
\hline $\begin{array}{l}\text { Extinction and } \\
\text { invasion risk }\end{array}$ & $\begin{array}{l}\text { Theory and analytical methods } \\
\text { well developed } \\
\text { Scale selection is arbitrary, } \\
\text { mechanistic link between scales of } \\
\text { processes or functions implicit } \\
\text { Data often limited }\end{array}$ & $\begin{array}{l}\text { Assessment of non-randomness of } \\
\text { ecological phenomena while } \\
\text { accounting for scaling } \\
\text { patterns in ecosystems }\end{array}$ & $\begin{array}{l}\text { Reduced uncertainty in risk } \\
\text { assessments at community and } \\
\text { population level (e.g. extinctions, } \\
\text { species invasions, fitness) } \\
\text { More mechanistic link between } \\
\text { spatial ecology (migration, } \\
\text { nomadism) and conservation } \\
\text { threats (e.g. habitat fragmentation) }\end{array}$ \\
\hline $\begin{array}{l}\text { Selection of } \\
\text { monitoring targets }\end{array}$ & $\begin{array}{l}\text { Surrogates for monitoring biodiversity } \\
\text { need to be cautiously applied } \\
\text { Based on normative values, for } \\
\text { example charismatic (flagship), } \\
\text { game, umbrella species } \\
\text { Limited connection to } \\
\text { ecosystem function }\end{array}$ & $\begin{array}{l}\text { Building on modern regime } \\
\text { shift theory } \\
\text { Based on objective, statistical } \\
\text { identification; species with } \\
\text { increased variability in } \\
\text { abundance (e.g. flickering) } \\
\text { Mechanistic link to system-level } \\
\text { processes and resilience }\end{array}$ & $\begin{array}{l}\text { Increasing cost-effectiveness of } \\
\text { monitoring programmes } \\
\text { Straightforward identification } \\
\text { of sentinel species indicating } \\
\text { environmental change } \\
\text { Identification of harbingers of } \\
\text { impending regime shifts }\end{array}$ \\
\hline
\end{tabular}

ish Monitoring of Lakes; Fölster et al. 2014) or cost, for example, through the use of remote sensing or real-time recording of biological data and their fast analysis (DNA barcoding) (Batt et al. 2013; Pettorelli et al. 2014; Rees et al. 2014). Nevertheless, several key questions remain as to how environmental change outcomes can be assessed cost-effectively, while accounting for the complex dynamics of ecosystems. We posit that discontinuity approaches have the potential to address this by selecting sets of species based on objective criteria that reflect relevant dynamics at the ecosystem scale.

The monitoring applications of discontinuity theory follow from several of our applications highlighted before, including the development of indicators of regime shifts and the non-randomness of ecological phenomena. Carpenter \& Brock (2006) suggested that certain key parameters of complex systems become more variable as they approach thresholds, for example when lakes change from a clear to a turbid state. Indicators for regime shifts have been proposed, such as increasing variance (Carpenter \& Brock 2006), flickering and increased autocorrelation (Scheffer et al. 2009), slowed recovery time after perturbation (Dakos et al. 2008), increased recovery length (i.e. distance necessary for connected populations to recover from spatial perturbations) (Dai, Korolev \& Gore 2013) and dynamic order (Eason, Garmestani \& Cabezas 2014). In this paper, we added the potential of discontinuity analysis to indicate regime shifts. It suggests that species located in the centre of aggregation groups may have a proportionally higher sensitivity to environmental perturbations and thus show heightened variability in response to stressors relative to those situated close to discontinuities, which may have a higher tolerance to perturbations. This provides methods to identify those species that are 
likely sensitive to change prior to systemic regime shifts, which would allow more targeted and effective monitoring to determine rapidly when there is an increased probability of an impending change to the regime of a system.

In practical terms, the discontinuity approach has the potential to reconcile the controversy around ecologically relevant monitoring based on single species approaches. Discontinuity analysis has the capacity to objectively identify those species that best capture ecological variability in ecosystems due to their location in the centre of body mass/size aggregations, regardless of their designation as flagship, economically important or umbrella species. Building on regime shift (early warning) theory, these species can serve as effective sentinels of environmental change where monitoring tracks their patterns of variability at scales where human impacts in ecosystems are the most severe. They may also serve as harbingers of regime shifts through focused monitoring of their variability in abundances over time and across body mass/size aggregation groups.

It is clear that discontinuities between scaling regimes represent areas where biodiversity and ecosystem processes are exposed to constant innovation and novelty under environmental change. This has profound implications for resilience and provides confirmation of cross-scale change in structuring regimes where individual, species and community turnover in time and space are indicative of both high variance and flickering. We are unaware that discontinuity approaches have been applied in monitoring programmes so far. However, given their potential, further research seems warranted to identify such sentinel species across ecosystem types and organism groups.

\section{Outlook and challenges}

Natural resource management is in need of practical, effective tools to understand ecosystem vulnerability and resilience to environmental change and to assess the biodiversity crisis at large. The examples discussed demonstrate that discontinuity analysis, and an extended version of it that accommodates taxa without discrete body mass/size data (e.g. spatial and time-series modelling; determination of scaling through power law relationships), provides a quantitative tool for this pursuit, complementing current management approaches (Table 1). Application of the discontinuity framework is recently gaining traction for the determination of relationships between functional diversity and resilience (Angeler et al. 2015a,b; Nash et al. 2015), and our overview shows further application of discontinuity analysis in ecology and management for assessing relationships between species extinctions, invasions, population fitness and ecosystem resilience. Ecosystems with high vulnerability can be identified through comparative assessments, helping to set management priorities. Discontinuity analysis also provides uncharted terrain for the exploration of impending regime shifts of individual systems, and to assist in objectively identifying the thresh- olds in ecological systems at which structures and processes change.

The general application of the discontinuity framework is limited because of data constraints (e.g. time-series and spatial data with sufficient resolution to cover relevant ecological scales) for most ecosystems and the lack of detailed trait knowledge for many organisms. This highlights the need for monitoring and improved trait information in concert with the application of discontinuity analysis, to create an iterative approach capable of capturing ecological complexity and variability over time. These, in combination with specifically designed experiments, provide opportunities for obtaining complementary and more mechanistic information about ecosystem structure and process.

Ecological management is goal-driven, and a complexity approach as presented in this paper may not be necessary to meet certain ends (e.g. creating biodiversity inventories). However, a thorough understanding of patterns and processes is needed for managing and conserving biodiversity and the manifold benefits human societies derive from it. To this end, it is useful to account for the complexity that is inherent in ecosystems to improve our knowledge of ecosystem responses to environmental change. The discontinuity framework shows how this complexity can be quantified, and ultimately provides opportunities to create a nexus between ecological theories in order to refine ecological impact assessment and improve environmental management.

\section{Acknowledgements}

The Nebraska Cooperative Fish and Wildlife Research Unit is jointly supported by a cooperative agreement between the U.S. Geological Survey, the Nebraska Game and Parks Commission, the University of NebraskaLincoln, the United States Fish and Wildlife Service and the Wildlife Management Institute. The views expressed herein are those of the authors and do not necessarily represent those of the United States Government or U.S. EPA. We gratefully acknowledge funding from the August T. Larsson Foundation of the Swedish University of Agricultural Sciences, the U.S. Geological Survey John Wesley Powell Center for Analysis and Synthesis and the Swedish Research Councils Formas (2014-1193) and Vetenskapsrådet (2014-5828). Joseph Bennett and two reviewers provided helpful comments that improved the paper. This paper is GLERL contribution number 1767 .

\section{Data accessibility}

Data have not been archived because this article does not contain data

\section{References}

Allan, J.D. \& Castillo, M.M. (2007) Stream Ecology. Springer, New York, NY.

Allen, C.R. (2006) Predictors of introduction success in the South Florida avifauna. Biological Invasions, 8, 491-500.

Allen, C.R., Forys, E.A. \& Holling, C.S. (1999) Body mass patterns predict invasions and extinctions in transforming landscapes. Ecosystems, 2, 114-121.

Allen, C.R., Gunderson, L. \& Johnson, A.R. (2005) The use of discontinuities and functional groups to assess relative resilience in complex systems. Ecosystems, 8, 958-966.

Allen, C.R. \& Holling, C.S. (2008) Discontinuities in Ecosystems and Other Complex Systems. Columbia University Press, New York, NY. 
Allen, C.R. \& Saunders, D.A. (2002) Variability between scales: predictors of nomadism in birds of an Australian Mediterranean-climate ecosystem. Ecosystems, 5, 348-359.

Allen, C.R. \& Saunders, D.A. (2006) Multi-model inference and the understanding of complexity, discontinuity, and nomadism. Ecosystems, 9, 694-699.

Allen, C.R., Angeler, D.G., Garmestani, A.S., Gunderson, L.H. \& Holling, C.S. (2014) Panarchy: theory and application. Ecosystems, 17, 578589

Angeler, D.G., Allen, C.R. \& Johnson, R.K. (2013) Measuring the relative resilience of subarctic lakes to global change: redundancies of functions within and across temporal scales. Journal of Applied Ecology, 50, 572584

Angeler, D.G., Göthe, E. \& Johnson, R.K. (2013) Hierarchical dynamics of ecological communities: do scales of space and time match? PLoS ONE, 8, e69174.

Angeler, D.G., Allen, C.R., Birgé, H.E., Drakare, S., McKie, B.G. \& Johnson, R.K. (2014a) Assessing and managing freshwater ecosystems vulnerable to environmental change. Ambio, 43(1 Suppl.), 113-125.

Angeler, D.G., Allen, C.R., Vila-Gispert, A. \& Almeida, D. (2014b) Fitness in animals correlates with proximity to discontinuities in body size distributions. Ecological Complexity, 20, 213-218.

Angeler, D.G., Allen, C.R., Uden, D.R. \& Johnson, R.K. (2015a) Spatial patterns and functional redundancies in a changing boreal lake landscape. Ecosystems, 18, 889-902.

Angeler, D.G., Baho, D.L., Allen, C.R. \& Johnson, R.K. (2015b) Linking degradation status with ecosystem vulnerability to environmental change. Oecologia, 178, 899-913.

Barnosky, A.D., Matze, N., Tomiya, S., Wogan, G.O.U., Swartz, B., Quental, T.B. et al. (2011) Has the Earth's sixth mass extinction already arrived? Nature, 471, 51-57.

Batt, R.D., Carpenter, S.R., Cole, J.J., Pace, M.L. \& Johnson, R.A. (2013) Changes in ecosystem resilience detected in automated measures of ecosystem metabolism during whole-lake manipulation. Proceedings of the National Academy of Sciences of the USA, 110, 17398-17403.

Boyle, W.A. \& Conway, C.J. (2007) Why migrate? A test of the evolutionary precursor hypothesis. The American Naturalist, 169, 344-359.

Burnett, C. \& Blaschke, T. (2003) A multi-scale segmentation/object relationship modelling methodology for landscape analysis. Ecological Modelling, 168, 233-249.

Carignan, V. \& Villard, M.-A. (2002) Selecting indicator species to monitor ecological integrity: a review. Environmental Monitoring and Assessment, 78, 45-61.

Carpenter, S.R. \& Brock, W.A. (2006) Rising variance: a leading indicator of ecological transition. Ecology Letters, 9, 311-318.

Colautti, R.I., Parker, J.D., Cadotte, M.W., Pysek, P., Brown, C.S., Sax, D.F. \& Richardson, D.M. (2014) Quantifying the invasiveness of species. NeoBiota, 21, 7-27.

Dai, L., Korolev, K.S. \& Gore, J. (2013) Slower recovery in space before collapse of connected populations. Nature, 496, 355-358.

Dakos, V., Scheffer, M., van Nes, E.H., Brovkin, V., Petoukhov, V. \& Held, H. (2008) Slowing down as an early warning signal for abrupt climate change. Proceedings of the National Academy of Sciences of the USA, 105, 14308-14312.

Eason, T., Garmestani, A.S. \& Cabezas, H. (2014) Managing for resilience: early detection of catastrophic shifts in ecological systems. Clean Technologies and Environmental Policy, 16, 773-783.

Elmqvist, T., Folke, C., Nyström, M., Peterson, G., Bengtsson, J., Walker, B. \& Norberg, J. (2003) Response diversity, ecosystem change and resilience. Frontiers in Ecology and the Environment, 1, 488-494.

Elphick, C.S. (2008) How you count counts: the importance of methods research in applied ecology. Journal of Applied Ecology, 45, 1313-1320.

Fauchald, P. \& Tveraa, T. (2006) Hierarchical patch dynamics and animal movement pattern. Oecologia, 149, 383-395.

Fischer, J., Lindenmayer, D.B., Blomberg, S.P., Montague-Drake, R., Felton, A. \& Stein, J.A. (2007) Functional richness and relative resilience of bird communities in regions with different land use intensities. Ecosystems, 10, 964-974.

Fölster, J., Johnson, R.K., Futter, M.N. \& Wilander, A. (2014) The Swedish monitoring of surface waters: 50 years of adaptive monitoring. Ambio, 43, 3-18.

Garmestani, A.S., Allen, C.R. \& Gunderson, L. (2009) Panarchy: discontinuities reveal similarities in the dynamic system structure of ecological and social systems. Ecology \& Society, 14, 15
Gaston, K.J. \& Blackburn, T.M. (1995) Birds, body size and the threat of extinction. Philosophical Transactions of the Royal Society of London B Biological Sciences, 347, 205-212.

Gillson, L. (2004) Evidence of hierarchical patch dynamics in an east African savanna? Landscape Ecology, 19, 883-889.

Göthe, E., Sandin, L., Allen, C.R. \& Angeler, D.G. (2014) Quantifying spatial scaling patterns and their local and regional correlates in headwater streams: implications for resilience. Ecology \& Society, 19, 15.

Graham, N.A.J., Jennings, S., MacNeil, M.A., Mouillot, D. \& Wilson, S.K. (2015) Predicting climate driven regime shifts versus rebound potential in coral reefs. Nature, 518, 94-97.

Gunderson, L.H. (2000) Ecological resilience theory and application. Annual Review of Ecology and Systematics, 31, 425-439.

Gunderson, L.H. \& Holling, C.S. (2002) Panarchy: Understanding Transformations in Human and Natural Systems. Island Press, Washington, DC.

Hamilton, M.A., Murray, B.R., Cadotte, M.W., Hose, G.S., Baker, A.C., Harris, C.J. \& Licari, D. (2005) Life-history correlates of plant invasiveness at regional and continental scales. Ecology Letters, 8, 1066-1074.

Haury, L.R., McGowan, J.A. \& Wiebe, P.H. (1978) Patterns and processes in the time-space scales of plankton distributions. Spatial Pattern in Plankton Communities (ed. J.H. Steele), pp. 277-327. Plenum, New York, NY.

Holling, C.S. (1973) Resilience and stability of ecological systems. Annual Review of Ecology and Systematics, 4, 1-23.

Holling, C.S. (1992) Cross-scale morphology, geometry, and dynamics of ecosystems. Ecological Monographs, 62, 447-502.

Hughes, T.P., Carpenter, S., Rockström, J., Scheffer, M. \& Walker, B. (2013) Multiscale regime shifts and planetary boundaries. Trends in Ecology and Evolution, 28, 389-395.

Hui, C., Richardson, D.M., Robertson, M.P., Wislon, J.R.U. \& Yates, C.J. (2011) Macroecology meets invasion ecology: linking the native distributions of Australian acacias to invasiveness. Diversity \& Distributions, 17, 872-883.

Kates, R.W., Travis, W.R. \& Wilbanks, T.J. (2012) Transformational adaptation when incremental adaptations to climate change are insufficient. Proceedings of the National Academy of Sciences of the USA, 109, 71567161.

Kefi, S., Rietkerk, M., Van Baalem, M. \& Loreau, M. (2007) Local facilitation, bistability and transitions in arid ecosystems. Theoretical Population Biology, 71, 367-379.

Kerkhoff, A.J. \& Enquist, B.J. (2007) The implications of scaling approaches for understanding resilience and reorganization in ecosystems. BioScience, 57, 489-499.

Leibold, M.A., Holyoak, M., Mouquet, N., Amarasekare, P., Chase, J.M., Hoopes, M.F. et al. (2004) The metacommunity concept: a framework for multi-scale community ecology. Ecology Letters, 7, 601613

Levin, S.A. (1992) The problem of patterns and scale in ecology. Ecology, 73, $1943-1967$.

Levin, S.A. (1998) Ecosystems and the biosphere as complex adaptive systems. Ecosystems, 1, 431-436.

Lindegren, M., Dakos, V., Gröger, J.P., Gårdmark, A., Kornilovs, G., Otto, S.A. \& Möllmann, C. (2012) Early detection of ecosystem regime shifts: a multiple method evaluation for management application. PLoS ONE, 7, e38410.

Lockwood, J.L., Hoopes, M.F. \& Marchetti, M.P. (2007) Invasion Ecology. Blackwell Publishing Ltd., Malden.

May, R.M. (1973) Stability in randomly fluctuating versus deterministic environments. The American Naturalist, 107, 621-650.

Nash, K.L., Allen, C.R., Angeler, D.G., Barichievy, C., Eason, T. Garmestani, A.S. et al. (2014a) Discontinuities, cross-scale patterns and the organization of ecosystems. Ecology, 95, 654-667.

Nash, K.L., Allen, C.R., Barichievy, C., Nyström, M., Sundstrom, S. \& Graham, N.A.J. (2014b) Habitat structure and body size distributions: cross-ecosystem comparison for taxa with determinate and indeterminate growth. Oikos, 123, 971-983.

Nash, K.L., Graham, N., Jennings, S., Wilson, S. \& Bellwood, D. (2015) Herbivore cross-scale redundancy supports response diversity and promotes coral reef resilience. Journal of Applied Ecology, doi: 10.1111/ $1365-2664.12430$

Nyström, M. (2006) Redundancy and response diversity of functiona groups: implications for the resilience of coral reefs. Ambio, 35, 30-35.

Peters, R.H. (1983) The Ecological Implications of Body Size. Cambridge University Press, New York, NY. 
Peterson, G.D., Allen, C.R. \& Holling, C.S. (1998) Ecological resilience, biodiversity, and scale. Ecosystems, 1, 6-18.

Pettorelli, N., Laurance, W.F., O'Brien, T.G., Wegmann, M., Nagendra, H. \& Turner, W. (2014) Satellite remote sensing for applied ecologists: opportunities and challenges. Journal of Applied Ecology, 51, 839-848.

Pimm, S.L. (1991) Balance of Nature? The University of Chicago Press, Chicago, IL.

Purvis, A., Gittleman, J.J., Cowlishaw, G. \& Mace, G.M. (2000) Predicting extinction risk in declining species. Proceedings of the Royal Society of London B: Biological Sciences, 267, 1947-1952.

Rees, H.C., Maddison, B.C., Middleditch, D.J., Patmore, J.R.M. \& Gough, K.C. (2014) The detection of aquatic animal species using environmental DNA - a review of eDNA as a survey tool in ecology. Journal of Applied Ecology, 51, 1450-1459.

Rietkerk, M., Deker, S.C., De Ruiter, P.C. \& Van de Koppel, J. (2004) Self-organized patchiness and catastrophic shifts in ecosystems. Science, 305, 1926-1929.

Rodrigues, A.S.L. \& Brooks, T.M. (2007) Shortcuts for biodiversity conservation planning: the effectiveness of surrogates. Annual Review of Ecology, Evolution, and Systematics, 38, 713-737.

Scheffer, M., Bascompte, J., Brock, W.A., Brovkin, V., Carpenter, S.R. Dakos, V. et al. (2009) Early-warning signals for critical transitions. $\mathrm{Na}$ ture, 461, 53-59.

Simberloff, D. (1998) Flagships, umbrellas, and keystones: is single-species management passé in the landscape era? Biological Conservation, 83 $247-257$.

Spanbauer, T.L., Allen, C.R., Angeler, D.G., Eason, T., Fritz, S.C., Garmestani, A.S., Nash, K.L. \& Stone, J.R. (2014) Prolonged instability prior to a regime shift. PLOS ONE, 9, e108936.

Standish, R.J., Hobbs, R.J., Mayfield, M.M., Bestelmeyer, B.T., Suding, K.N., Battaglia, L.L. et al. (2014) Resilience in ecology: abstraction, distraction, or where the action is? Biological Conservation, 177, 43-51.

Stow, C., Allen, C.R. \& Garmestani, A.S. (2007) Evaluating discontinuities in complex systems: toward quantitative measures of resilience. Ecology and Society, 12, 26
Sundstrom, S.M., Allen, C.R. \& Barichievy, C. (2012) Species, functional groups, and thresholds in ecological resilience. Conservation Biology, 26, 305-314.

Sundstrom, S.M., Angeler, D.G., Garmestani, A.S., García, J.H. \& Allen, C.R. (2014) Transdisciplinary application of cross-scale resilience. Sustainability, 6, 6925-6948.

Urban, D.L., O’Neill, R.V. \& Shugart, H.H. Jr (1987) Landscape ecology. BioScience, 37, 119-127.

Wardwell, D. \& Allen, C.R. (2009) Variability in population abundance is associated with thresholds between scaling regimes. Ecology and Society, 14, 42

Wheatley, M. \& Johnson, C. (2009) Factors limiting our understanding of ecological scale. Ecological Complexity, 6, 150-159.

Wiens, J.A. (1989) Spatial scaling in ecology. Functional Ecology, 3, 385397.

Wu, J. \& Loucks, O.L. (1995) From balance of nature to hierarchical patch dynamics: a paradigm shift in ecology. The Quarterly Review of Biology, 70, 439-466.

Yachi, S. \& Loreau, M. (1999) Biodiversity and ecosystem productivity in a fluctuating environment: the insurance hypothesis. Proceedings of the National Academy of Sciences of the USA, 96, 1463-1468.

Received 29 January 2015; accepted 29 June 2015

Handling Editor: Joseph Bennett

\section{Supporting Information}

Additional Supporting Information may be found in the online version of this article.

Appendix S1. Glossary with definitions of terms. 